\title{
DISCIPLINAS SEMIPRESENCIAIS COMO METODOLOGIA DE ENSINO E APRENDIZAGEM NA PERCEPÇÃO DA GESTÃO
}

\author{
SEMIPRESENCIAL DISCIPLINES AS TEACHING AND LEARNING METHODOLOGY \\ IN PERCEPTION OF MANAGEMENT
}

\author{
ASIGNATURAS SEMIPRESENCIALES COMO METODOLOGÍA DE ENSEÑANZA Y \\ APRENDIZAJE EN LA PERCEPCIÓN DE LA GESTIÓN
}

Vera Rejane Coelho* vrejane5o@gmail.com

Sabrina Bet**

sabrina.uniplac@gmail.com

Vanice dos Santos ${ }^{* * *}$

vanicedossantos@gmail.com

REVISTA PEDAGÓGICA

Revista do Programa de Pós-graduação em Educação da Unochapecó | ISSN 1984-1566

Universidade Comunitária da Região de Chapecó | Chapecó-SC, Brasil Como referenciar este artigo: COELHO, V. R.; BET, S.; SANTOS, V. Disciplinas semipresenciais como metodologia de ensino e aprendizagem na percepção da gestão. Revista Pedagógica, Chapecó, v. 19, n. 41, p. 302-316, maio./ago. DOI: http://dx.doi.org/10.22196/rp.v19i41.3702

RESUMO: Este texto versa sobre uma pesquisa realizada de 2013 a 2015, sobre a implantação de disciplinas semipresenciais, na modalidade de Educação a Distância (EaD) utilizando-se $20 \%$ da carga horária total do curso, conforme Portaria $n^{0} 4.059 / 2004$. A EaD como modalidade educacional surgiu com a Lei $\mathrm{n}^{0}$ 9.394/96 - Lei de Diretrizes e Bases (LDB), regulamentada pelo Decreto $\mathrm{n}^{\circ} 5.622 / 2005$. O objetivo foi analisar a implantação dessa modalidade como metodologia de ensino na percepção da Pró-Reitora de Ensino, de alunos e professores de sete cursos de licenciatura, de uma Universidade Comunitária em Santa Catarina. A metodologia da pesquisa consistiu na observação, em registros dos encontros com professores e alunos e de dados do setor de Avaliação Institucional, além da pesquisa bibliográfica/documental para a fundamentação teórica. Foi possível observar a resistência dos alunos no início dos cursos; porém, no processo, os estudantes foram se revelando receptivos quanto ao uso de recursos tecnológicos e a liberdade de estudar em horários alternativos e que o perfil do professor era determinante no processo. Quanto aos professores resistentes a $\mathrm{EaD}$, demonstravam sua rejeição aos alunos e, quanto maior tempo de docência, maior a resistência.

ABSTRACT: This paper aims to develops some arguments on the research made from 2013 until 2015 about the implementation of semipresential disciplines, in the modality of $\mathrm{EaD}$ using $20 \%$ of the total time of the course, according to Ordinance $\mathrm{n}^{0} 4.059 / 2004$. The $\mathrm{EAD}$ as an educational modality emerged with Law $\mathrm{n}^{0}$ 9.394/96 (LDB), regulated by Decree $n^{0} 5.622 / 2005$. The objective was to analyze the implementation of this modality as a teaching methodology in the perception of the Pro-Rectory of Teaching, of students and teachers of seven undergraduate courses, of a Community University in Santa Catarina. Our research methodology consisted on observation, records of meetings with teachers and students, data from the Institutional Evaluation sector, as well as a bibliographical/documentary research for the theoretical grounds. It was possible to observe the resistance of the students at the beginning of the courses, however, in the process they were revealing their receptivity on the use of technological resources and the freedom to study in alternative schedules. Also the profile of the teacher was determinant in the process. As it concerns the teachers who resisted to $\mathrm{EaD}$, they showed their rejection to the students and longer they taught, more resistant they became.

Keywords: Semipresential Discipline. Education on Distance. Pedagogical Management.

Palavras-chave: Disciplina Semipresencial. Educação a Distância. Gestão pedagógica.

RESUMEN: Este texto versa sobre una investigación realizada de 2013 a 2015, sobre la implantación de asignaturas semipresenciales, en la modalidad de Educación a Distancia (EaD) utilizándose 20\% de la carga horaria total del curso, conforme Portaria $\mathrm{n}^{\mathrm{o}}$ 4.059/2004. La EaD como modalidad educacional surgió con la Ley no 9.394/96 - Lei de Diretrizes e Bases (LDB), reglamentada por el Decreto $n^{0} 5.622 / 2005$. El objetivo fue analizar la inserción de esa modalidad como metodología de enseñanza en la percepción de la Pro Rectoría de Enseñanza, de alumnos y profesores de siete carreras universitarias de una Universidad Comunitaria en Santa Catarina. La metodología de la investigación 
* Professora do ensino superior, Mestre em Educação. Ênfase em cursos de formação de professores.

** Professora do ensino superior, Mestre em Educação. Ênfase em cursos de Sistemas de Informação.

*** Professora, Doutora do programa de PósGraduação em Educação da Universidade do Planalto Catarinense (Uniplac). consistió en la observación, registros de los encuentros con profesores y alumnos, datos del sector de Evaluación Institucional, y hacemos uso de la pesquisa bibliográfica/documental para la fundamentación teórica. Fue posible observar resistencia de los alumnos al inicio de los cursos, sin embargo, en el proceso fueron revelándose receptivos cuanto al uso de recursos tecnológicos y la libertad de estudiar en horarios alternativos y que el perfil del profesor era determinante en el proceso. Cuanto a los profesores resistentes a la EaD, demostraban ese rechazo a los alumnos y, cuanto mayor tiempo de docencia, mayor el rechazo.

Palabras Clave: Asiganturas semi-presenciales. Educación a distancia. Gestión pedagógica.

\section{INTRODUÇÃO}

Desde 2006, a instituição, lócus desta pesquisa, tem regulamentada uma política específica para os cursos de licenciaturas que já tenham passado pelo processo de reconhecimento. Nesta política consta o compartilhamento entre os cursos de disciplinas de formação geral, quais sejam: Língua Portuguesa, Produção Acadêmica, Filosofia da Educação, Teorias da Aprendizagem, Políticas Públicas para a Educação Básica, Didática e Pesquisa e Prática Pedagógica, sendo uma a cada semestre, excetuado o oitavo, em que não há compartilhamento. Em 2012, essas mesmas disciplinas passaram a ser desenvolvidas de forma semipresencial, com uso dos recursos tecnológicos e metodológicos da Educação a Distância (EaD), respaldado pela Portaria $\mathrm{n}^{0}$ 4.059 $\mathrm{n}^{0}$ 4.059, de 10 de dezembro de 2004, que aprova e regulamenta a destinação de $20 \%$ da carga horária total de cursos presenciais à oferta nesta modalidade.

No contexto deste trabalho, utiliza-se o conceito de Educação a Distância apontado por Moore e Kearsley (2008 apud MILL, 2013, p. 22), que a consideram como um "[...] aprendizado planejado que ocorre normalmente em um lugar diferente do local do ensino, exigindo técnicas especiais de criação do curso e de instrução, comunicação por meio de várias tecnologias e disposições organizacionais e administrativas especiais". Para o conceito de semipresencialidade, ou modalidade semipresencial, toma-se como referência a Portaria $n^{0} 4.059 / 2004$, que o define como o conjunto de quaisquer atividades didáticas, módulos ou unidades de ensino-aprendizagem centradas na autoaprendizagem com a mediação de recursos didáticos organizados em diferentes suportes de informação que utilizem tecnologias de comunicação remota (BRASIL, 2004).

Sendo assim, esta pesquisa se justifica pela necessidade de registrar o acompanhamento dessa implantação, pois é uma experiência nova para a maioria dos professores que atuam nos cursos de licenciatura da referida instituição. Além disso, os alunos se matriculam nesta instituição em virtude de sua tradição de educação presencial. Inicialmente, professores e alunos se colocaram resistentes a essa implantação.

A implantação desta metodologia que se utiliza de recursos midiáticos e tecnológicos está fundamentada na 
necessidade de aproximar os alunos, futuros professores, do uso de recursos tecnológicos, bem como na perspectiva do desenvolvimento de habilidades e competências de autonomia, espírito investigativo, interação com os colegas e o professor, por meio dos fóruns e debates e, ainda, de responsabilidade no cumprimento das tarefas e dos prazos estabelecidos. Outra questão que suscitou essa mudança de metodologia foi o fato de que ainda se observa o processo de ensino centrado do professor, ou seja, há uma grande preocupação com o ensino e pouca análise em relação à aprendizagem do aluno. Tarcia e Cabral (2010, p. 19) destacam que "[...] muitas instituições de ensino superior (IES) têm investido nessa prática como forma de inovação, de dinamização da situação presencial”.

Nesta metodologia, o aluno, por meio do acesso ao Ambiente Virtual de Aprendizagem (AVA), tem conhecimento da organização didática do professor. Isso faz com que as fragilidades dos professores fiquem mais evidentes. Previsto isso, antes da implantação da proposta, foram desencadeados vários encontros em que se discutiu nos colegiados sobre a prática pedagógica dos professores dos cursos que são os formadores desses futuros professores e, portanto, a quem cabe também apresentar outras possibilidades metodológicas além da que utiliza quadro-negro, giz ou aparelhos de projeção.

Vive-se em um mundo eminentemente tecnológico, não há dúvida. Mas, virá a educação escolar acompanhando essa evolução? O uso desses recursos vem sendo discutido e inserido de fato como possibilidade metodológica para ressignificar o processo de ensino e aprendizagem na formação e também na atuação dos professores? Estes questionamentos são inevitáveis quando se faz referência a essa sociedade tecnológica, e a escola é parte determinante dessa sociedade.

Como a instituição lócus da pesquisa tem uma cultura muito forte de educação presencial, isso fez com que o processo inicial da implantação dessa proposta fosse visto com desconfiança pelos alunos e com muito descrédito pelos professores, gerando alguns embates. Era, contudo, necessário romper com essas barreiras, inclusive porque o uso de recursos tecnológicos como metodologia de ensino tem sido amplamente difundido desde a década de 1980, quando as Tecnologias de Informação e Comunicação (TIC) passaram a tomar lugar de destaque em todos os setores da sociedade. Inclusive, documentos que norteiam tanto o currículo da base nacional comum quanto o currículo para a formação de professores para a Educação Básica, como Lei $n^{0}$ 9.394/96 - Lei de Diretrizes e Bases (LDB) -, e Resolução CNE/CP no 2, de $1^{\circ}$ de julho de 2015 - Diretrizes Curriculares Nacionais para Formação Inicial e Continuada em Nível Superior para Profissionais do Magistério para a Educação Básica, enfatizam tal necessidade sob pena de a escola e os cursos de formação de professores ficarem desconectados da realidade da educação brasileira. 
Inicialmente, a EaD foi recebida e vista como uma ameaça à educação presencial até então ofertada na instituição. A questão recorrente sempre foi a qualidade dos cursos de graduação, principalmente na formação de professores, que são ofertados nessa modalidade. Com as reuniões e as oficinas ofertadas tanto a alunos quanto a professores, isso foi dissipando-se. Na medida em que os envolvidos foram percebendo que a modalidade presencial não precisava competir com a $\mathrm{EaD}$, e vice-versa, ambas com suas características e especificidades devem trabalhar para a oferta de uma educação significativa e qualificada.

$\mathrm{Na}$ formação de professores, seja em cursos presenciais, seja em EaD, o importante é a utilização de fundamentos e metodologias capazes de contribuir para o desenvolvimento da capacidade do aluno de ler e analisar o seu meio e o meio em que vivem seus alunos. Isso passa pelo uso de conhecimentos tecnológicos e de inovação, pois o mundo hoje é tecnológico. Os documentos que norteiam a Educação Básica no Brasil apontam para essa necessidade desde a educação infantil, acentuando-a no Ensino Fundamental, Médio, Educação de Jovens e Adultos (EJA), além da educação profissional. No currículo do Ensino Médio, a Lei no 9.394/96 destaca a importância da educação tecnológica básica, nesta etapa da escolarização, pois o estudante deve ter o "domínio dos princípios científicos e tecnológicos que presidem a produção moderna" (BRASIL, 1996, p. 18). Isso pode facilitar a conexão entre o jovem, o seu mundo e o mundo do trabalho.

Para tanto, a discussão do uso das tecnologias de informação e comunicação na educação implica repensar a própria formação de professores, tendo em vista que é ele, o professor, quem faz a mediação entre o conhecimento científico e o conhecimento prévio dos alunos, de maneira que possam construir seus próprios conhecimentos. As Diretrizes Curriculares Nacionais para Formação Inicial e Continuada em Nível Superior para Profissionais do Magistério para a Educação Básica (BRASIL, 2015, p. 3) abordam esta questão:

No exercício da docência, a ação do profissional do Magistério da educação básica é permeada por dimensões técnicas, políticas, éticas e estéticas por meio de sólida formação, envolvendo o domínio e manejo de conteúdos e metodologias, diversas linguagens, tecnologias e inovação, contribuindo para ampliar a visão e a atuação do profissional.

Além dessa premissa, também consta no referido documento (2015, p. 6) a importância do "[...] uso competente das tecnologias de informação e comunicação (TIC) para o aprimoramento da prática pedagógica e a ampliação da formação cultural dos professores(as) e estudantes". Portanto, é praticamente impossível pensar em educação escolar do século XXI sem fazer referência a uma prática 
pedagógica permeada por recursos tecnológicos, pois esse é o meio em que o alunado vive e convive diariamente.

Essa breve contextualização se fez necessária para melhor compreender a importância da utilização de recursos tecnológicos na dinamização das metodologias de ensino e aprendizagem, rompendo com metodologias tradicionais que concebem o ensino e a aprendizagem como duas dimensões que subsistem separadamente. As Diretrizes Curriculares Nacionais para a Educação Básica (BRASIL, 2010, p. 25) propõem que: “[...] essa distância necessita ser superada, mediante a aproximação dos recursos tecnológicos de informação e comunicação, estimulando a criação de novos métodos didático-pedagógicos, para que tais recursos e métodos sejam inseridos no cotidiano escolar".

Nessa perspectiva, a oferta de disciplinas semipresenciais - em que a interação entre professor e aluno é mediada pelos recursos tecnológicos e educacionais da EaD - permite pensar em outra forma de trabalhar a docência. O aluno e o professor não estão presentes no mesmo espaço e em um mesmo tempo, mas a comunicação é facilitada por diversos recursos midiáticos, e estes podem ter maior abrangência e melhor resultado do que os obtidos no tempo restrito da aula presencial, fechada em sala. Ainda assim, para que esses aspectos se tornem "[...] possibilidade concreta de construção coletiva e colaborativa de novas práticas pedagógicas, coerentes com o momento sócio-histórico no qual estamos inseridos [...]" (CARLINI; TARCIA, 2010, p. 3), o professor, independentemente do nível de atuação, precisa assumir uma vontade/postura inovadora.

Em um espaço educacional com forte tradição de educação presencial, todavia, como os alunos receberam a proposta, considerando que, ao matricularem-se, o fizeram em um curso presencial? Qual foi a reação dos professores que historicamente vinham ministrando as referidas disciplinas presencialmente? Como ficou registrada qual seria a conduta do professor ao trabalhar com essas disciplinas? Essas são algumas questões que buscamos responder no texto que segue.

Registra-se que a metodologia utilizada nesta pesquisa foi de caráter qualitativo, embora em alguns casos, no decorrer do processo, tenham sido analisados dados quantitativos, como na pesquisa da avaliação institucional. Foi uma pesquisa que se utilizou de fontes bibliográficas, documental e pesquisa de campo, a qual se deu por meio da observação participante e dos registros das reuniões com alunos e professores, bem como do resultado da avaliação institucional sobre o grau de satisfação dos alunos com a EaD realizada no sétimo semestre dos cursos.

\section{BREVE HISTÓRICO DA EDUCAÇÃO A DISTÂNCIA}

O art. 80 da LDB de 1996, que trata da Educação a Distância, foi regulamentado pelo Decreto $\mathrm{n}^{\mathbf{0}} \mathbf{5 . 6 2 2}$, 
de 19 de dezembro de 2005 , definindo conceitos e formas de operacionalização. Segundo o Decreto, esta modalidade de educação se caracteriza pela "[...] mediação didático-pedagógica nos processos de ensino e aprendizagem [que] ocorre com a utilização de meios e tecnologias de informação e comunicação, com estudantes e professores desenvolvendo atividades educativas em lugares ou tempos diversos". Esse conceito está diretamente ligado à própria história da $\mathrm{EaD}$; afinal, ao contrário do que parece, não é uma modalidade de ensino recente.

No Brasil, remonta ao início do século XX, quando já se praticava, não da forma como conhecemos, que envolve recursos tecnológicos de alta qualidade, mas já sem que fosse necessária a presença física do aluno junto ao professor. A Associação Brasileira de Educação a Distância (ABEN, 2015, p. 14), entretanto, apresenta uma experiência de um professor de taquigrafia dos Estados Unidos da América, que, em 1728, já utilizava um método de ensino por correspondência, que pode ser caracterizado como o início da EaD. Em 1922, com o advento da Primeira Guerra Mundial, era utilizada inicialmente "[...] para a rápida capacitação de soldados durante o conflito e, posteriormente, as experiências serviram para preparar e integrar populações obrigadas a emigrar" (ABED, 2015, p. 16). São, logo, quase 300 anos em que essa modalidade de ensino tem sido difundida no mundo. No entanto, foi com a internet e suas TICs que se promoveu a ampla expansão da EaD (MAIA, 2002).

No Brasil, as iniciativas mais contundentes nessa área são datadas do fim do século XIX e início do século XX e eram restritas a uma ou outra iniciativa. Alves (2011, p. 87) aponta que, em 1904, saiu "uma nota no Jornal do Brasil oferecendo, por correspondência, curso de datilografia". Este início, por correspondência, parece ser comum nesta modalidade de ensino, evoluindo posteriormente para o rádio e a televisão com a tele-educação, de modos que foram acompanhando a evolução das mídias de comunicação até alcançar as digitais de alta tecnologia.

Alves (2011, p. 90) destaca que, já a partir da década de 1980, há registro de que "[...] fundações privadas e organizações não governamentais iniciaram a oferta de cursos supletivos a distância, no modelo de tele-educação, com aulas via satélite, complementadas por kits de materiais impressos"; todavia, para Belloni (2009), a internet é o principal veículo mediador da transmissão de conhecimentos, criando um meio de comunicação cujas possibilidades dependem da tecnologia utilizada e do planejamento da instituição.

Portanto, essa modalidade de Ensino já se consolidou como uma proposta de educação democrática, de caráter social e de grande abrangência. A publicação Lei $\mathrm{n}^{\circ}$ 9.394/96 (art. 80) definiu que caberia ao Poder Público incentivar "[...] o desenvolvimento e a veiculação de programas de ensino a distância, em todos os níveis e 
modalidades de ensino e de educação continuada”. A oferta desta modalidade de ensino se justifica pela exigência da mesma Lei, que determina, no art. 62, a formação mínima para o exercício da docência. No Brasil, havia muitos professores em sala de aula sem formação para tal modalidade.

A formação de docentes para atuar na educação básica far-se-á em nível superior, em curso de licenciatura, de graduação plena, em universidades e institutos superiores de educação admitida, como formação mínima para o exercício do magistério na educação infantil e nos 5 (cinco) primeiros anos do ensino fundamental, a oferecida em nível médio na modalidade normal. (BRASIL, 2013, [s. p.]).

Portanto, em vista da falta de professores habilitados, a EaD possibilitou o rompimento das barreiras espaciais e temporais, oportunizando aos excluídos dos mais diferentes lugares do Brasil a chance de participar de uma formação educacional. O que se iniciou como uma proposta para formação de professores que já vinham atuando passou a representar em muitos casos a única possibilidade de formação de professores.

As características da EaD se aplicam à oferta da semipresencialidade, pois também há a utilização dos recursos tecnológicos de informação e comunicação como metodologia, permitindo "[...] dinamizar o processo de ensino/ aprendizagem, introduzindo um novo paradigma na relação aluno/professor, em que ambos têm novas responsabilidades e novos perfis" (OLIVEIRA; FERREIRA; DIAS, 2004, [s. p.]).

\section{DISCIPLINAS SEMIPRESENCIAIS: 20\% DA CARGA HORÁRIA DO CURSO}

Em 2004, o Ministério da Educação (MEC) publicou a Portaria $n^{0} 4.059 / 2004$, autorizando Instituições de Ensino Superior "a oferecerem até $20 \%$ da carga horária das disciplinas, ou do total da carga horária de um curso de graduação presencial, a distância, por meio da utilização de tecnologias próprias de EaD” (TARCIA; CABRAL, 2010, p. 17). $\mathrm{O}$ art. $1^{\mathrm{O}}$ do referido documento define que

[...] as instituições de ensino superior poderão introduzir, na organização pedagógica e curricular de seus cursos superiores reconhecidos, a oferta de disciplinas integrantes do currículo que utilizem modalidade semipresencial, com base no art. 81 da Lei no 9.394 , de 1996, e no disposto nesta Portaria. (BRASIL/MEC, 2004, [s. p.]).

O que a Portaria autorizou foi a utilização de uma parte da carga horária de cursos e/ou disciplinas presenciais para que fossem desenvolvidas atividades pedagógicas 
com o uso das tecnologias da EaD. Para Tarcia e Cabral (2010, p. 18), "[...] essa prática dos $20 \%$ define uma situação chamada de semipresencial ou semipresencialidade, como é definida na Portaria $\mathrm{n}^{0} 4.059$, de 10 de dezembro de 2004". Conceitualmente, essa Portaria define a modalidade semipresencial com base na sala de aula virtual capaz de comportar diferentes meios de construção do conhecimento associados aos materiais didáticos e TICs sob uma interface integrada para facilitar o processo de ensino-aprendizagem a distância (CAMPOS; COSTA; SANTOS, 2007).

Segundo a Associação Brasileira de Educação a Distância (ABED), em seu Relatório Analítico da Aprendizagem a Distância no Brasil do ano de 2014, registra 3.453 cursos ou disciplinas semipresenciais oferecidas pelas instituições formadoras. Deste total, 1.288, ou 37\%, consistem em cursos de graduação - bacharelado e licenciatura, com 519 cursos, $14 \%$ do total. O documento ainda aponta que, tanto nos cursos totalmente a distância, quanto nos cursos e/ou disciplinas semipresenciais, a área de maior abrangência em 2014 foi Ciências Sociais, com 33\% da amostra total, ficando as Ciências Humanas em segundo lugar, com $14 \%$ do total. O relatório revela, ainda, que a maior concentração de curso totalmente a distância está na pós-graduação - 53\% do total -, e os semipresenciais ou disciplinas semipresenciais se concentram nos níveis de graduação, em um total de 70\% (ABED, 2015, p. 48-49).

No ano de 2015, o Censo EAD (ABED, 2016) sugere uma inversão nos níveis, pois revela que o maior índice de matrícula em cursos e/ou disciplinas semipresenciais está nos bacharelados. Nos ofertados totalmente a distância, o maior número de matrículas está concentrado nas licenciaturas e nos cursos que formam tecnólogos.

Embora os números da semipresencialidade se concentrem nos bacharelados, justifica-se a importância desse método de ensino e aprendizagem na formação inicial e continuada do docente. Tarcia e Cabral (2010, p. 20) afirmam que a decisão de ofertar essa modalidade de educação deve estar embasada em ética e profissionalismo, visto que é necessário oportunizar ao aluno vivências efetivas da "[...] dimensão a distância de seu curso ou disciplina com garantias concretas de qualidade do ensino. Ele deve sair da sala de aula para buscar novos conhecimentos e desenvolver novas habilidades e atitudes, a partir de situações ricas, coerentes e inovadoras".

O acompanhamento da gestão pedagógica vai desde o momento em que foi definido este processo até que se estabeleça de forma consistente a interface entre o professor e o aluno, o aluno, o professor e as ferramentas de aprendizagem, ou seja, até que se crie uma sinergia entre todos os envolvidos, sob pena de ter de reverter todo o processo, considerando-se que se refere a uma instituição que não tem cursos em EaD. Assim, na sequência, apontaremos algumas questões que ficaram evidentes no processo de acompanhamento da implantação da modalidade semipresencial na referida instituição. 
1 Dentro dos 20\% da carga horária do curso, com a utilização dos recursos tecnológicos da educação a distância.

\section{O QUE FOI OBSERVADO}

Como já mencionado, esta pesquisa está fundamentada na metodologia da observação e acompanhamento da implantação das disciplinas semipresenciais ${ }^{1}$ nos cursos de História, Geografia, Letras, Pedagogia, Educação Física, Matemática e Ciências Biológicas. A opção pelos referidos cursos se dá pelo fato de serem estes os que tiveram entrada de alunos no primeiro semestre de 2013, com previsão de término no segundo semestre de 2016.

Registra-se que a reorganização dos Projetos Pedagógicos dos cursos foi aberta para a participação dos integrantes dos colegiados dos cursos, como, portanto, um processo aberto em que todos tiveram conhecimentos das mudanças em relação à semipresencialidade. Este foi um marco para as licenciaturas: o início de um processo de inovação na metodologia e estratégias de ensino e aprendizagem "que valorizem o autoaprendizado dos alunos" (MENDES; SERMANN, 2007, p. 2).

A gestão desse processo foi coordenada pela Pró-Reitoria de Ensino, envolvendo a avaliação institucional, setor de $\mathrm{EaD}$ e as coordenações de cursos. Para Mendes e Sermann (2007, p. 4), a gestão de um programa dessa magnitude requer não só uma equipe qualificada mas também um investimento financeiro capaz de contemplar as necessidades desse tipo de educação. Apesar disso, segundo os mesmos autores, acima de tudo "[...] é importante assumi-lo como investimento ético referido ao compromisso com o desenvolvimento pleno dos cidadãos e oferta igualitária de oportunidade a todos" (MENDES; SERMANN, 2007, p. 4). Para isso, um trabalho coletivo, colegiado permite que as decisões não sejam tomadas de forma solitária e isoladas, até porque esta é uma política institucional.

Neste trabalho coletivo, o papel dos coordenadores de curso foi indispensável, tendo em vista ser ele que representa a instituição e o curso frente aos professores e alunos. Portanto, a forma da apresentação do curso, no início do primeiro semestre letivo, é decisiva para que o aluno aceite a proposta metodológica da semipresencialidade sem maiores transtornos - lembrando que este aluno matriculou-se em um curso presencial. Esta apresentação deve ser no sentido de valorizar esta proposta, apresentando a plataforma como um ótimo recurso para o desenvolvimento de atividades diferenciadas por meio de fóruns, debates e tarefas previamente definidas no plano de ensino além das avaliações da aprendizagem.

Nesse processo de apresentação, houve problemas nos cursos de Letras e Educação Física. Nestes casos, foi necessária a presença do Reitor e da Pró-Reitoria de Ensino para mediar o conflito que se instalou, devido a não compreensão e à recusa de alguns alunos da aula semipresencial. "Eu me matriculei em um curso presencial. Não quero ensino a distância", "se fosse para fazer educação a distância, teria me matriculado no concorrente de vocês": 
essas foram algumas das falas dos alunos que, ao se recusarem a aceitar a proposta, tiveram dificuldades de percebê-lo como um avanço para a aprendizagem. Dois meses após o início das aulas, houve desistência de cerca de $20 \%$ dos alunos do curso. A justificativa foi que se haviam matriculado em um curso presencial, e não a distância.

Outro dado significativo, comum aos cursos de Pedagogia, História e Geografia, foram as reclamações sobre a disciplina "Língua Portuguesa", que, segundo os alunos, deveria ser presencial, em função da defasagem que a maioria apresentava. Alguns estudantes estavam há muito tempo sem estudar, outros tinham defasagem vinda do Ensino Médio. Destaca-se que nesta instituição há um programa de nivelamento com aulas de Língua Portuguesa em três horários diferenciados para contemplar todos os alunos; no entanto, dificilmente os alunos destes cursos frequentavam as aulas do reforço. Os cursos de Matemática e Ciências Biológicas não fizeram nenhuma reclamação formal; porém, sempre havia comentários pejorativos e em tom de desaprovação manifestados aos professores do semestre.

Uma das estratégias encontradas para minimizar o descontentamento dos alunos foi um trabalho no laboratório de informática cujo objetivo foi apresentar as qualidades do ambiente virtual de aprendizagem (AVA), incentivando a cultura do acesso e do uso dos recursos tecnológicos como facilitador do processo de ensino e aprendizagem, em que o aluno também é sujeito produtor do seu conhecimento. Nesta etapa, é fundamental o envolvimento da coordenação do curso e de professores que falem a mesma linguagem. Isso precisou ocorrer com maior esforço nos dois primeiros semestres do curso.

A partir do segundo ano, as reclamações dos alunos foram dissipando-se, invertendo-se os sujeitos. O professor começou a manifestar insatisfação em relação à postura dos alunos frente ao desenvolvimento das atividades de aprendizagem disponibilizadas e mediadas no AVA. Nessa situação, a figura do tutor que integra a equipe da $\mathrm{EaD}$ foi de extrema importância fazendo o papel de incentivador, motivador dos alunos. E, neste processo, os sujeitos ficam mais expostos. As fragilidades dos professores e dos alunos ficam mais evidenciadas. Os alunos passaram a questionar o perfil do professor que trabalha com esta proposta metodológica.

Observa-se que nesses professores a preparação das aulas ainda segue o modelo tradicional de aula expositiva, conteúdos teóricos repassados e organizados pelo professor, planilha de avaliação em relação direta com o plano de aula, que deve ser rigorosamente cumprido, e a internet como repositório de conteúdos. Esse diagnóstico do desempenho docente permite identificar os professores envolvidos no Programa EaD em relação ao uso dos produtos disponíveis e dos recursos que deles derivam para suas práticas docentes (MENDES; SERMANN, 2007, p. 12). 
2 Ver: <http://www.semesp.org.br/site/ semesp-lanca-pesquisa-ead-2016/>.
Os problemas apontados pelos autores são mais evidenciados em relação aos professores com maior tempo de docência na instituição. Considerado "responsável pela disciplina", o representante dessa classe cria resistência antes mesmo do início das aulas. Tem dificuldades com o manuseio da plataforma e quase sempre não participa do programa de formação para trabalhar com a EaD. Tarcia e Cabral (2010, p. 19) afirmam que inclusive "[...] alguns professores, de forma equivocada, consideram que a tecnologia poderá ocupar o lugar deles na sala de aula e que, dessa forma, eles poderão ser substituídos”. Na perspectiva de dar continuidade ao processo, neste caso, a gestão optou por buscar outros docentes da instituição para compor a equipe em prol de um trabalho inovador, comprometido com uma educação capaz de fazer a diferença na formação do aluno.

Como todo o processo de inovação, a avaliação precisa ser exercitada constantemente. Neste caso, a avaliação institucional foi parceira permanente. Isso contribuiu para a revisão constante dos problemas da implantação das disciplinas semipresenciais por meio do emprego da metodologia e dos recursos tecnológicos da EaD que surgiram no processo, possibilitando à equipe gestora a resolução dos entraves no menor tempo possível.

\section{CONSIDERAÇÕES FINAIS}

Toda e qualquer mudança em um primeiro momento tende a causar desconforto ou resistência. Isso é próprio do ser humano. Em uma instituição que traz consigo uma cultura de quase 60 anos de educação presencial, a implantação da educação a distância pode ser vista como uma ameaça a essa tradição de compartilhamento do mesmo espaço/tempo entre alunos e professores.

Romper com esses paradigmas passa pela compreensão de que a EaD não é apenas mais uma experiência educacional, e sim uma modalidade educacional que somente no Brasil (2015) contempla, conforme o Sindicato das Mantenedoras de Ensino Superior (SEMESP), aproximadamente 1,3 milhão de alunos matriculados; destes, 1,2 milhão estão na rede privada e 139 mil na pública" ${ }^{2}$. Portanto, pode-se considerar como uma modalidade de educação que atingiu seu objetivo - romper com a barreira do tempo e do espaço em relação à formação acadêmica dos brasileiros. Muitos mitos, porém, ainda são levantados quando se discute EaD em espaços de educação presencial.

Os resultados obtidos em relação aos alunos revelam, mesmo em uma instituição que tem uma cultura forte de educação presencial, que não há uma rejeição forte em relação à $\mathrm{EaD}$ em si; a maior dificuldade dos alunos é em relação à metodologia e à disciplina no uso frequente dos recursos tecnológicos. Um dado revelado pelos alunos que se mostrou significativo é o fato de estes apontarem que o sucesso da disciplina depende do perfil do professor. 
Professores com maior tempo de casa e que se revelam contra a EaD não conseguem adaptar-se, e as fragilidades aparecem de forma contundente. Destaca-se que esta pesquisa foi realizada em 2016, tendo como base de informações o ano de 2015. Essa resistência, muitas vezes, dá-se pela desinformação dos sujeitos, ou mesmo pelo fator cultural.

Mesmo quando se propõe a implantação da modalidade semipresencial com o uso dos recursos tecnológicos da educação a distância considerando os 20\% da carga horária total do curso, requer-se da gestão pedagógica capacidade de motivação e convencimento para alunos e professores. Neste caso, revelou-se exatamente isto: resistência de ambos, professores e alunos. Inclusive, muitas das reclamações dos alunos eram a reprodução das falas dos seus professores.

E, apesar de se recuperar a confiança dos alunos em relação à certeza de que todo o processo seria acompanhado e avaliado constantemente, eram constantes as comparações entre uma modalidade e outra nas reuniões dos colegiados de curso. Além disso, os professores subestimavam os alunos em relação ao uso dos recursos do AVA e de outros instrumentos tecnológicos.

$\mathrm{O}$ que ficou mais evidente neste processo foi a maior capacidade de amadurecimento e aceitação em relação à nova proposta por parte dos alunos e as fragilidades e resistências dos professores. Outra questão levantada nas últimas avaliações institucionais foi a necessidade de rever o perfil do professor para trabalhar com a EaD. Observou-se que, quanto maior o tempo de docência na referida instituição, maior a resistência em compreender e experienciar propostas de inovação de recursos e metodologia. Em menor percentual, os cursos de Educação Física e Letras mantiveram-se resistentes até o término da graduação; justamente nestes colegiados estão os professores mais antigos na instituição. O curso de Pedagogia se manteve instável; dependendo do professor, tal era o andamento da disciplina. Este foi o curso que apresentou alunos com maiores problemas em relação aos acessos e cumprimentos de tarefas no AVA.

Nos cursos de História, Geografia, Matemática e Ciências Biológicas houve uma redução significativa da resistência dos alunos. Em muitos momentos, ouviram-se depoimentos sobre a importância do uso dos recursos tecnológicos de forma mais sistematizada. Também foram percebendo que a organização das disciplinas oferecidas na modalidade semipresencial era muito maior do que nas disciplinas presenciais. Em uma reunião com representantes dos cursos em questão, houve comentários como: "nas disciplinas na $\mathrm{EaD}$, ficamos sabendo já no início do semestre o que vamos ter de fazer ao longo do semestre, não há surpresas".

Desse processo de gestão da implantação dessa metodologia, ficaram mais dúvidas do que certezas. Em todo início de ano letivo, há novos cursos utilizando-se dessa 
política. Muitos cursos de formação para professores que têm interesse em trabalhar com recursos de $\mathrm{EaD}$ foram oferecidos pela instituição, normalmente duas vezes ao ano. A maioria dos professores que, ao longo da implantação, manifestaram estar descontentes e/ou desaprovarem o método nunca participou desses cursos. Outros professores se destacaram com atitude e competências importantes para a EaD. A equipe do setor igualmente foi amadurecendo e tornou-se referência para os alunos.

Diante do exposto, poderíamos afirmar que esse processo deu uma base considerável para que o setor alçasse novos desafios; porém, no fim do ano de 2016, por motivos financeiros, a instituição optou por trocar os gestores pedagógicos, e outra ação foi o encerramento das atividades da equipe do setor de $\mathrm{EaD}$, ficando apenas dois tutores prestando atendimento aos alunos. Parte desse encerramento das atividades foi resultado do poder de convencimento principalmente dos professores que se mostraram contrários ou resistentes à implantação das disciplinas semipresenciais. Essa é uma situação comum em instituições privadas com características de instituição pública.

\section{REFERÊNCIAS}

ALVES, Lucineia. Educação a distância: conceitos e história no Brasil e no mundo. Associação Brasileira de Educação a Distância,v. 10, p. 84-92, 2011. Disponível em: <http://www.abed.org.br/revistacientifica/Revista_ PDF_Doc/2011/Artigo_07.pdf>. Acesso em: 13 out. 2016.

ASSOCIAÇÃO BRASILEIRA DE EDUCAÇÃO A DISTÂNCIA. Censo EAD.BR: Relatório Analítico da Aprendizagem a Distância no Brasil 2014. Curitiba: Ibpex, 2015 .

ASSOCIAÇÃO BRASILEIRA DE EDUCAÇÃO A DISTÂNCIA. Censo EAD.BR: Relatório Analítico da Aprendizagem a Distância no Brasil 2015. Curitiba: Ibpex, 2016.

BELLONI, Maria Luiza. Educação a distância. 5. ed. São Paulo: Autores Associados, 2009.

BRASIL. Lei no 9.394, de 20 de dezembro de 1996. Estabelece as diretrizes e bases da educação nacional. Diário Oficial da República Federativa do Brasil, Brasília, DF, 21 dez. 1996b. Disponível em: <http://www. planalto.gov.br/ccivil_03/_Ato2011-2014/2014/Lei/ L13005.htm>. Acesso em: 20 set. 2016.

BRASIL. Ministério da Educação. Portaria $n^{0} 4.059$, de 10 de dezembro de 2004. Diário Oficial da República Federativa do Brasil, Brasília, DF, 13 dez. 2004. Disponível em: <http://portal.mec.gov.br/sesu/arquivos/ 
pdf/nova/acs_portaria4059.pdf $>$. Acesso em: 20 dez. 2016.

BRASIL. Decreto $\mathrm{n}^{0}$ 5.622, de 19 de dezembro de 2005. Regulamenta o art. 80 da Lei $n^{0}$ 9.394, de 20 de dezembro de 1996, que estabelece as diretrizes e bases da educação nacional, 2005. Diário Oficial da República Federativa do Brasil, Brasília, DF, 19 dez. 2005. Disponível em: <http://www.planalto.gov.br/ccivil_03/_ ato2004-2006/2005/decreto/d5622.htm>. Acesso em: 14 dez. 2016.

BRASIL. Ministério da Educação. Resolução $\mathrm{CNE} / \mathrm{CP}^{0}{ }^{0}$ 2, de $1^{0}$ de julho de 2015. Define as Diretrizes Curriculares Nacionais para a formação inicial em nível superior (cursos de licenciatura, cursos de formação pedagógica para graduados e cursos de segunda licenciatura) e para a formação continuada. Disponível em: <portal. mec.gov.br/docman/julho-2015-pdf/17719-res-cnecp-002-03072015>. Acesso em: 14 dez. 2016.

CAMPOS, Fernanda Cláudia Alves; COSTA, Rosa Maria Esteves Moreira da; SANTOS, Neide dos. Fundamentos da educação à distância, mídias e ambientes virtuais. Juiz de Fora: Editar, 2007.

CARLINI, Alda Luiza; TACIA, Rita Maria. 20\% a distância: e agora?: orientações práticas para o uso de tecnologia de educação a distância. São Paulo: Pearson Education do Brasil, 2010. p. 17-26

MAIA, Carmem. Guia brasileiro de educação a distância. São Paulo: Esfera, 2002.

MENDES, Ana Maria Coelho Pereira; SERMANN, Lucia Izabel Czerwonka. Estratégias para implantação de educação a distância e virtualização nos cursos de graduação em uma organização de educação superior. 2007. Disponível em: <http://www.anpae. org.br/congressos_antigos/simposio2007/xxx03.pdf $>$. Acesso em: 15 jan. 2016.

MILL, Daniel. Ensino e aprendizagem na educação virtual: noções elementares para educadores e gestores. In: MILL, Daniel; MACIEL, Cristiano (Org.). Educação a distância: elementos para pensar o ensino aprendizagem contemporâneo. Cuiabá: EdUFMT, 2013, p. 19-36.

OLIVEIRA, Eloiza da Silva Gomes de; FERREIRA, Aline Campos da Rocha; DIAS, Alessandra Cardoso Soares. Tutoria em educação a distância: avaliação e compromisso com a qualidade. 2004. Disponível em: <http://www.abed.org.br/congresso2004/por/htm/155TC-D2.htm>. Acesso em: 12 jan. 2017. 
SINDICATO DAS MANTENEDORAS DE ENSINO SUPERIOR. Semesp lança pesquisa EaD 2016. 16 jun. 2016. Disponível em: <http://www.semesp.org.br/ site/semesp-lanca-pesquisa-ead-2016/>. Acesso em: 14 dez. 2016.

TARCIA, Rita Maria Lino; CABRAL, Ana Lúcia Tinoco. Implantação de $20 \%$ a distância nas instituições de ensino. In: CARLINI, Alda Luiza; TACIA, Rita Maria. 20\% a distância: e agora?: orientações práticas para o uso de tecnologia de educação a distância. São Paulo: Pearson Education do Brasil, 2010. p. 17-26

UNIVERSIDADE DO PLANALTO CATARINENSE. Plano de desenvolvimento institucional. Lages: UNIPLAC, 2010.

Recebido em: 13/03/2017 Aprovado em: 08/05/2017 